\title{
Volcanic ash detection and retrievals using MODIS data by means of neural networks
}

\author{
M. Picchiani ${ }^{1}$, M. Chini ${ }^{2}$, S. Corradini ${ }^{2}$, L. Merucci ${ }^{2}$, P. Sellitto ${ }^{3}$, F. Del Frate ${ }^{1}$, and S. Stramondo ${ }^{2}$ \\ ${ }^{1}$ Dipartimento di Informatica Sistemi e Produzione - Tor Vergata University, Rome, Italy \\ ${ }^{2}$ Istituto Nazionale di Geofisica e Vulcanologia, Rome, Italy \\ ${ }^{3}$ Laboratoire Inter-universitaire des Systèmes Atmosphériques (LISA), UMR7583, Universités Paris-Est et Paris Diderot, \\ CNRS, Créteil, France
}

Received: 11 April 2011 - Published in Atmos. Meas. Tech. Discuss.: 4 May 2011

Revised: 21 November 2011 - Accepted: 22 November 2011 - Published: 7 December 2011

\begin{abstract}
Volcanic ash clouds detection and retrieval represent a key issue for aviation safety due to the harming effects on aircraft. A lesson learned from the recent Eyjafjallajokull eruption is the need to obtain accurate and reliable retrievals on a real time basis.

In this work we have developed a fast and accurate Neural Network (NN) approach to detect and retrieve volcanic ash cloud properties from the Moderate Resolution Imaging Spectroradiometer (MODIS) data in the Thermal InfraRed (TIR) spectral range. Some measurements collected during the 2001, 2002 and 2006 Mt. Etna volcano eruptions have been considered as test cases.

The ash detection and retrievals obtained from the Brightness Temperature Difference (BTD) algorithm are used as training for the NN procedure that consists in two separate steps: ash detection and ash mass retrieval. The ash detection is reduced to a classification problem by identifying two classes: "ashy" and "non-ashy" pixels in the MODIS images. Then the ash mass is estimated by means of the NN, replicating the BTD-based model performances. A segmentation procedure has also been tested to remove the false ash pixels detection induced by the presence of high meteorological clouds. The segmentation procedure shows a clear advantage in terms of classification accuracy: the main drawback is the loss of information on ash clouds distal part.

The results obtained are very encouraging; indeed the ash detection accuracy is greater than $90 \%$, while a mean RMSE
\end{abstract}

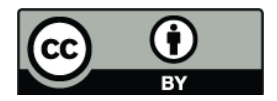

Correspondence to: M. Picchiani (picchian@disp.uniroma2.it) equal to $0.365 \mathrm{t} \mathrm{km}^{-2}$ has been obtained for the ash mass retrieval. Moreover, the NN quickness in results delivering makes the procedure extremely attractive in all the cases when the rapid response time of the system is a mandatory requirement.

\section{Introduction}

The recent Eyjafjallajokull eruption clearly showed that the real time detection and tracking of the volcanic ash cloud evolution based on satellite data, plays a key role in the management of aviation crisis. Because of the well known harming effects of volcanic ash cloud particles on aircraft (abrasion of turbine blades, windscreens, fuselage, and Pitot static tubes, loss of power and in extreme cases failure of highbypass turbine engines, see Miller and Casadevall, 2000) many European airports were closed causing millions of passengers to be stranded with a worldwide airline industry loss estimated of about 2.5 billion Euros (EUMETSAT Report, 2010). Both security and economical grounds necessitate a great effort to realize reliable and robust ash cloud detection and retrieval on a real time basis.

Because of the sporadic nature and the large spatial extent of the volcanic ash clouds, satellite remote sensing represents the most suitable tool to address the problem. The most widely used approach to detect volcanic ash is based on the Brightness Temperature Difference (BTD) procedure applied to the channels centered around 11 and $12 \mu \mathrm{m}$ (Prata, 1989a). Using this approach the volcanic ash mass retrieval is carried out from the simulated Top Of Atmosphere (TOA) radiances

Published by Copernicus Publications on behalf of the European Geosciences Union. 
computed by means of radiative transfer models (Wen and Rose, 1994; Yu et al., 2002). The BTD technique has been applied either to polar satellite instruments as the Advanced Very High Resolution Radiometer (AVHRR) (Prata, 1989b; Wen and Rose, 1994), the Moderate Resolution Imaging Spectroradiometer (MODIS) (Hillger et al., 2002; Watson et al., 2004; Tupper at al., 2004; Corradini et al., 2008a, 2010, 2011), rather than to geostationary satellite instruments as the Geostationary Operational Environmental Satellite (GOES) (Yu et al., 2002), and the Spin Enhanced Visible and Infrared Imager (SEVIRI) measurements (Prata and Kerkmann, 2007; Corradini et al., 2008b). The use of radiative transfer models has two main drawbacks: the need of several inputs and the processing time. The latter can be so high that utilization during the crisis phases becomes extremely difficult.

Since the beginning of the 1990s the Neural Networks (NNs) (Lippmann, 1987) have been exploited to analyze remote sensing data (Atkinson and Tatnall, 1997; Mas and Flores, 2008). Several authors have highlighted the effectiveness of the NNs in the observation of the Earth's environment from space. In particular the capability to learn by example and generalize also in a noisy environment make NNs attractive for the supervised classification as well as for retrieval application from remotely sensed data. The generalization ability (see universal approximator theorem, Cybenko, 1989; Hornik et al., 1989) and the independence from a priori constrains about the data distributions (Civco, 1993; Benediktsson and Sveinsson, 1997; Carpenter et al., 1997) represent two of the most attractive advantages of NNs with respect to other inversion algorithms. Furthermore NNs are able to positively combine different types of input data, i.e. data acquired from different sensors (Benediktsson et al., 1993; Chini et al., 2009; Pacifici et al., 2009), as well as to incorporate independent knowledge and realistic physical constraints into the analysis (Foody, 1995a, b), properties of great interest for remote sensing applications. The comparison of statistical classification methods and NNs has shown that NNs can achieve more accurate results (Benediktsson et al., 1990, 1993; Chini et al., 2008). In the field of atmospheric investigations the NNs have been successfully used to address different problems such as: humidity profiles retrieval (CabreraMercader and Staelin, 1995; Blackwell, 2005), height resolved ozone retrievals (Del Frate and Schiavon, 1999; Del Frate et al., 2002; Müller et al., 2003; Sellitto et al., 2011a, b), cloud classification (Lee et al., 1990; Bankert, 1994), temperature parameter esteems (Butler et al., 1996) and retrieval of temperature profiles (Churnside et al., 1994). For a further reading about NNs for the solution of atmospheric inverse problems that involve complex physical behaviors see Gardner and Dorling (1998) and Hsieh and Tang (1998).

In this work we present an innovative approach in which the capability of the NNs is exploited to obtain accurate and reliable volcanic ash detection and retrievals in order to sample the cloud evolution. In particular, we highlight that in a NN based algorithm the time cost is transferred to the
Table 1. MODIS TIR channels characteristics.

\begin{tabular}{lrrr}
\hline $\begin{array}{l}\text { Channel } \\
\text { no. }\end{array}$ & $\begin{array}{r}\text { Center } \\
\text { Wavelength } \\
(\mu \mathrm{m})\end{array}$ & $\begin{array}{r}\text { NEDT } \\
(\mathrm{K})\end{array}$ & $\begin{array}{r}\text { Spatial } \\
\text { Resolution } \\
(\mathrm{km})\end{array}$ \\
\hline 28 & 7.3 & 0.25 & 1 \\
29 & 8.5 & 0.05 & 1 \\
30 & 9.7 & 0.25 & 1 \\
31 & 11.0 & 0.05 & 1 \\
32 & 12.0 & 0.05 & 1 \\
\hline
\end{tabular}

preliminary training phase, thus permitting the processing of satellite images in near real time. The proposed methodology can be readily extended to the study of ash emission of other volcanoes making the NNs approach very appealing.

\section{MODIS instrument}

The MODerate resolution Imager Spectroradiometer (MODIS) is a multi-spectral instrument aboard the Earth Observing System (EOS) Terra and Aqua polar satellites (Barnes et al., 1998; http://modis.gsfc.nasa.gov/). Terra's descending node (from north to south) crosses the equator in the morning while the Aqua ascending node (south to north) crosses the equator in the afternoon with a global coverage in 1 or 2 days. MODIS covers 36 spectral bands, from visible (VIS) to thermal infrared (TIR), and a spatial resolution that varies from $250 \mathrm{~m}$ to $1000 \mathrm{~m}$, depending on the acquisition mode. A summary of the TIR channels characteristics is given in Table 1.

In the present work the bands 31 and 32, centered around 11 and $12 \mu \mathrm{m}$ respectively, have been used for volcanic ash detection and retrievals by using the Brightness Temperature Difference (BTD) procedure (see Sect. 4). In the NNs approach (see Sect. 5) the band 28, centered around $7.3 \mu \mathrm{m}$, is also used to account for the atmospheric water vapor effect on ash detection (Corradini et al., 2008a).

\section{Test cases}

Mt. Etna volcano $\left(37.73^{\circ} \mathrm{N}, 15.00^{\circ} \mathrm{E}\right)$ is a massive stratovolcano located in the eastern part of Sicily (Italy). With a summit elevation of $3330 \mathrm{~m}$, it is the largest and most active European volcano and one of the major degassing volcanoes in the world. Its eruptive activity occurs nearly every year both at the summit's four craters and on the flanks.

During the eruptions significant emissions of gases (mainly $\mathrm{H}_{2} \mathrm{O}, \mathrm{CO}_{2}$ and $\mathrm{SO}_{2}$, Allard et al., 1991; Aiuppa et al., 2008) and ash can be injected into the atmosphere. Ash fallout periodically reaches the surrounding areas affecting the local population and disrupting activities at the nearby airports of Catania, Sigonella, and Reggio Calabria. 

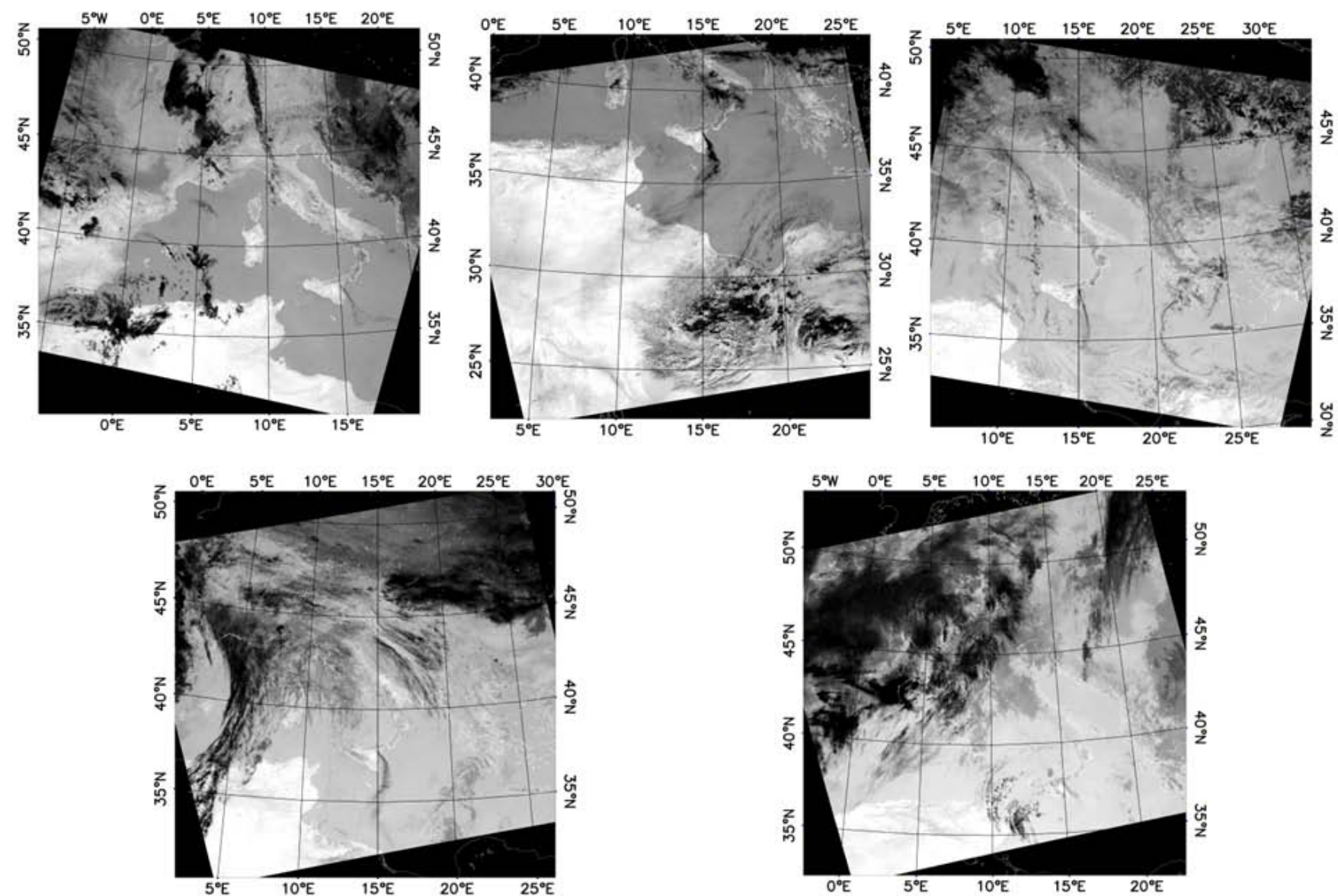

Fig. 1. Channel 31 MODIS test case images. Top Plates, from left to right: 23 July 2001 at 10:35 UTC; 28 October 2001 at $12: 15$ UTC and 29 October 2002 at 12:05 UTC. Bottom Plates, from left to right: 30 October 2002 at 9:45 UTC and 24 November 2006 at 12:20 UTC.

In this work five acquisitions from MODIS-Terra and MODIS-Aqua instruments, collected during the 2001 (23 July at 10:35 UTC), $2002(28,29$ and 30 October at 12:15, 9:45 and 12:05 UTC, respectively) and 2006 (24 November at 12:20 UTC) Mt. Etna eruptions, have been considered to test the methodology. Figure 1 shows the five MODIS channel 31 images: the ash cloud is clearly identifiable southeast of the volcano.

The considered MODIS dataset is representative of different volcano eruption typologies (high and medium ash emissions) occurred during different seasons (spring, autumn and winter).

\section{Brightness Temperature Difference procedure}

The Brightness Temperature Difference (BTD) procedure used for the volcanic ash detection, exploiting the selective absorption in the TIR spectral range, is based on the difference between the brightness temperatures of two TIR channels centered on 11 and $12 \mu \mathrm{m}$ (Prata, 1989a, b). The main BTD advantage is its very simple and fast application, while the main drawbacks are the false alarms ("false positive" when a particular pixel is recognized as ash affected but that in fact doesn't contain ash and vice-versa for "false negative") obtained in specific and well documented cases (Simpson et al., 2000; Prata et al., 2001), as over clear land surfaces at night (Platt and Prata, 1993), over soils with a high quartz content (e.g. deserts) (Barton and Takashima, 1986), over very cold surfaces (Potts and Ebert, 1996), over ice-covered surfaces (Yamanouchi et al., 1987) and in presence of high water vapour content (Prata et al., 2001; Yu et al., 2002; Corradini et al., 2008a). This latter effect, that tends to attenuate and in some cases can completely cancel-out the BTD signal, has been corrected by applying a procedure developed by Corradini et al. (2008a). The ash mass is computed in each pixel by using the simplified formula suggested by Wen and Rose (1994) exploiting the ash density, the pixel size, the ash extinction efficiency factor, the effective radius $\left(r_{\mathrm{e}}\right)$ and optical depth $(\tau), r_{\mathrm{e}}$ and $\tau$ are obtained from the Top Of Atmosphere (TOA) simulated "inverted arches" BTD curves vs. brightness temperature at $11 \mu \mathrm{m}$ (Wen and Rose, 1994; Prata and Grant, 2001; Yu et al., 2002). 

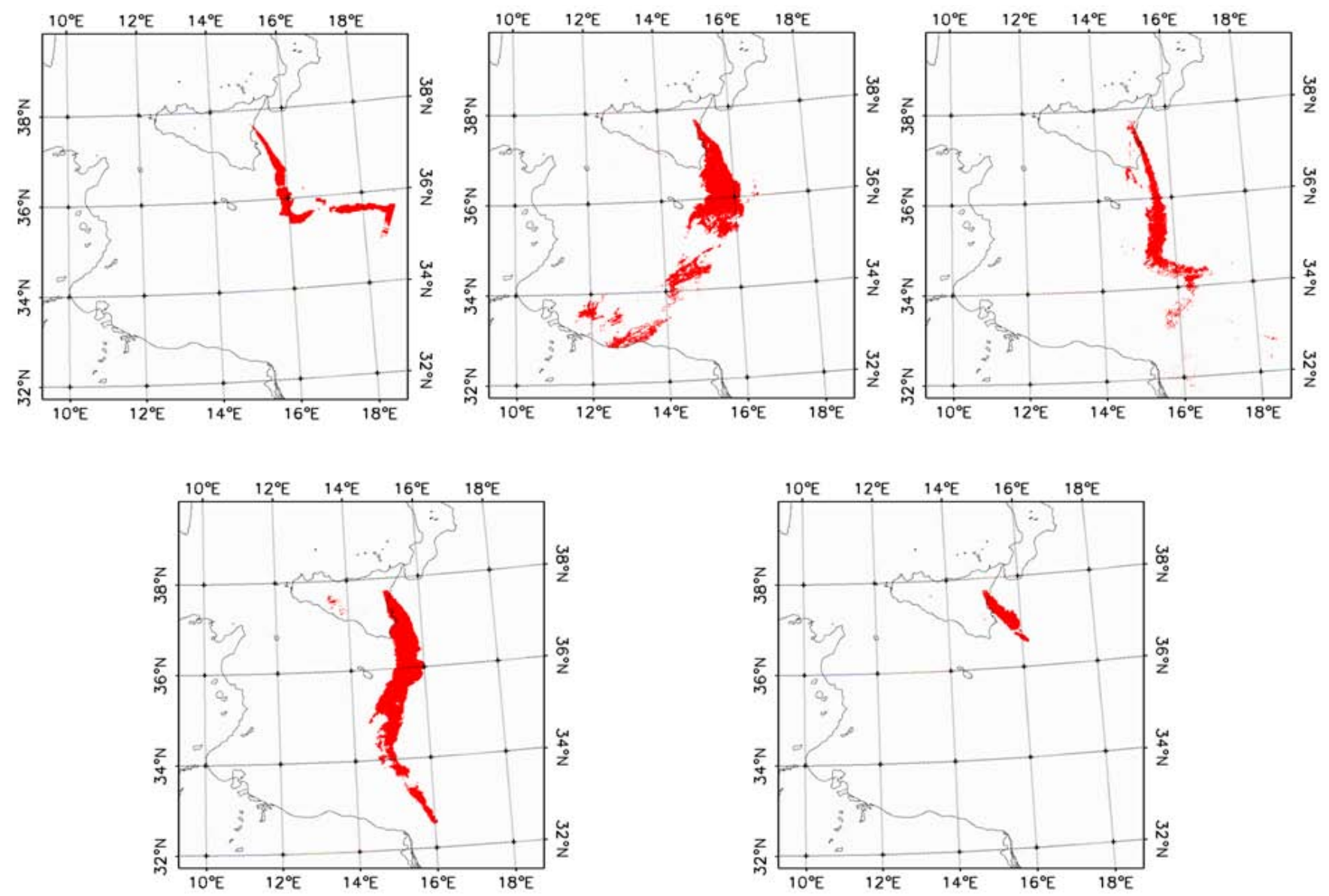

Fig. 2. MODIS BTD ash detection maps. Top Plates, from left to right: 23 July 2001, 28 October 2002 and 29 October 2002. Bottom Plates, from left to right: 30 October 2002 and 24 November 2006 .

The simulated TOA radiances Look-Up Table (LUT) needed for the ash retrievals are computed by using the MODTRAN 4 (Berk et al., 1998; Anderson et al., 1995) Radiative Transfer Model (RTM). The inputs to MODTRAN are the atmospheric profiles of Pressure, Temperature and Humidity (PTH), the surface characteristics (temperature and emissivity), the volcanic plume altitude and thickness, and the volcanic ash optical properties. In this work all the atmospheric profiles have been collected at the Trapani WMO Meteo Station (the meteorological station situated nearest to the volcanic area). In all the cases considered in this study the ash clouds were mainly located over the sea; therefore the surface emissivity has been set equal to 0.99 for both 11 and $12 \mu \mathrm{m}$ channels (see the ASTER spectral emissivity library database, http://speclib.jpl.nasa.gov/). The surface temperature is computed by inverting the radiative transfer equation in the TIR spectral range. The volcanic cloud altitude has been derived from the comparison between the $11 \mu \mathrm{m}$ brightness temperature of the ash cloud most opaque pixels and the WMO atmospheric temperature profiles (see Prata and Grant, 2001; Corradini et al., 2008a). The ash optical properties are derived using a Mie code (EODG, Oxford University) using the Volz et al. (1973) refractive index. The density of ash has been set to $2.6 \times 10^{6} \mathrm{~g} \mathrm{~m}^{-3}$ (Neal et al., 1994). The final set of RTM simulations, computed in a multiple scattering atmosphere (16 streams), uses 801 wavelengths (from 700 to $1500 \mathrm{~cm}^{-1}$, step $1 \mathrm{~cm}^{-1}$ ) $\times 15$ angles (from 0 to $75^{\circ}$, step $\left.5^{\circ}\right) \times 9$ optical depths (from 0 to 10 , constant step in a logarithmic scale) $\times 8$ particle effective radii (from 0.7 to $10 \mu \mathrm{m}$, constant step in a logarithmic scale). The total computational time for each LUT, considering a personal computer (Intel dual core processor $2.13 \mathrm{GHz}$ ) is about $4 \mathrm{~h}$.

Every MODTRAN input parameter is affected by a certain uncertainty that cause errors in the ash retrievals. A $40 \%$ of total ash mass retrieval error has been considered, following the sensitivity study carried out by Corradini et al. (2008a) which considered the uncertainties of many parameters such as atmospheric profiles, plume geometry, surface temperature and emissivity and ash type.

Figures 2 and 3 show the ash detection and retrieval maps, respectively, for the 5 MODIS test case measurements. The retrievals show the huge amount of ash emitted during the 

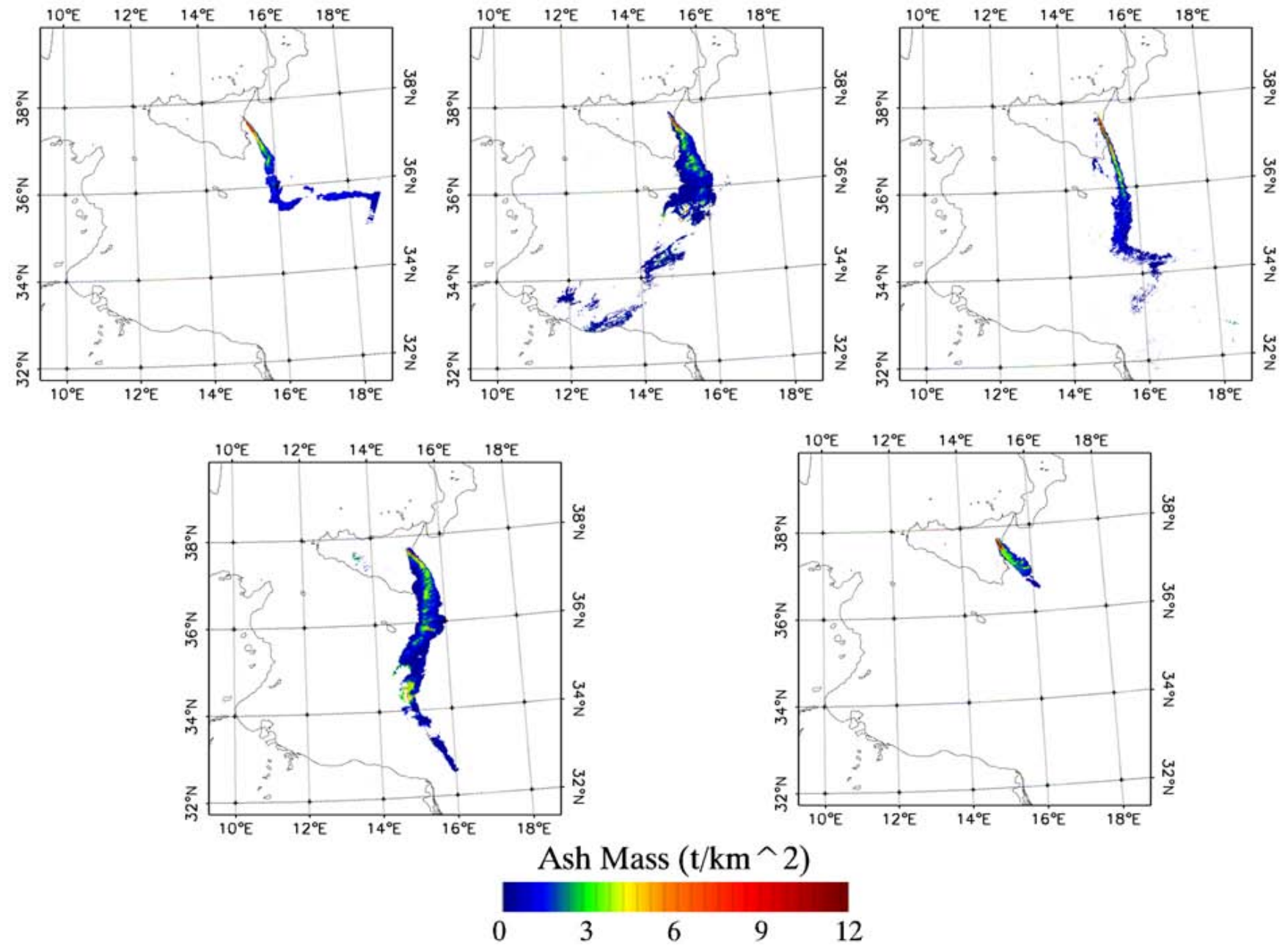

Fig. 3. MODIS BTD ash retrieval maps. Top Plates, from left to right: 23 July 2001, 28 October 2001 and 29 October 2002. Bottom Plates, from left to right: 30 October 2002 and 24 November 2006.

2001 and 2002 eruption events, affecting the south Mediterranean area and north Africa. The 2006 ash emission was significantly lower, limiting the problems to the area surrounding Etna and the Fontanarossa airport in Catania.

\section{Neural Network approach}

In this section the Neural Network (NN) methodology for the ash detection and retrieval is described.

The NNs are statistical-mathematical models able to extract the underlying relationships between a given number of input and output quantities. In this work we have considered a particular type of NNs known as feed-forward multilayer perceptron (MLP) (Bishop, 1995; Haykin, 1994). MLP-NNs are composed of elementary computational units called neurons, organized in layers. Usually we have one Input layer, one Output layer and one or more Hidden layers (Funahashi, 1989). The elements of each layer are connected to the elements of adjacent layers with weighted links, and the signal propagates from one layer to the next only in the inputoutput (forward) direction. Each neuron accepts as input a combination of the outputs from the neurons of the previous layer, and processes it by means of its Activation Function $(\mathrm{AF})$, which is in general non-linear (sigmoidal activation function). The NNs is considered to be a method that realizes a non-linear regression between sets of inputs and outputs, where weights are the free parameters. The regression is done during the learning stage by the progressive and iterative adjustment of the weights, on the basis of a set of examples data, also called training patterns. At each cycle of the learning stage the error, between the outputs computed by the $\mathrm{NN}$ and the known true outputs is computed and the weight are changed in order to minimize the error. In this way the information contained in the training set is transferred to the NN architecture. To test the generalization of the regression a cross-validation technique can be applied using 

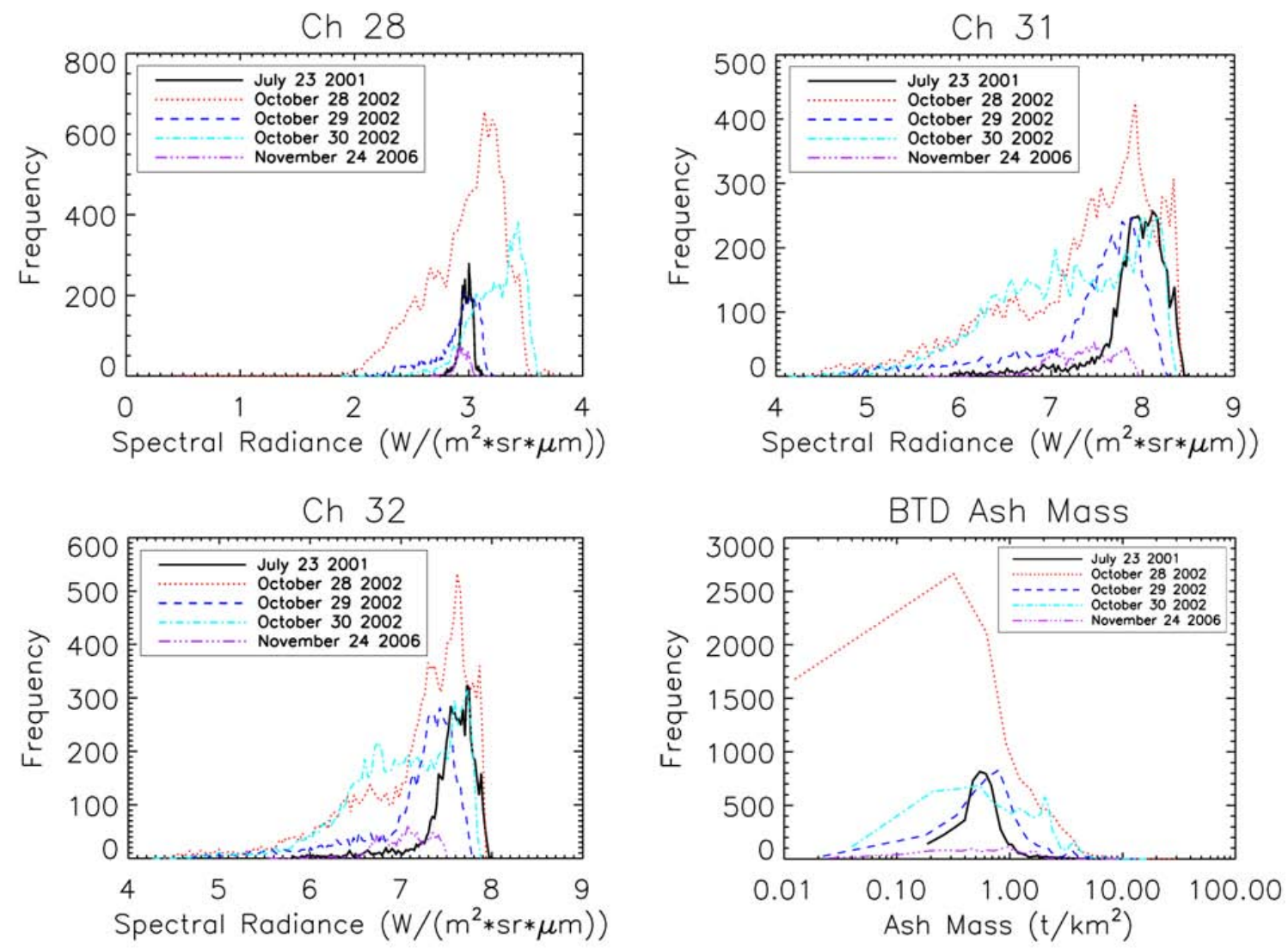

Fig. 4. The histograms computed for the three considered MODIS channels and for the BTD ash mass esteemed values, for the five considered acquisition date. Top Plates, from left to right: MODIS CH28 and $\mathrm{CH} 31$. Bottom Plates, from left to right: MODIS CH32 and BTD Total mass esteemed values.

an independent set of patterns, also called test set. Relying on the NN capability of discovering appropriate functional mapping between the input and the output spaces, we have used the MLP-NN to approximate the linking function between the measured quantity, i.e. the brightness temperature in the three considered MODIS channels, and the quantity of interest, like the presence of ash and its mass. Considering that the $\mathrm{NN}$ extrapolates the information directly from the data, the correct choice of the inputs to the NN could be very important when addressing the inversion problem. Geophysical conditions should be taken into consideration. In this work, for instance, we used the TIR MODIS channels because these are the most sensitive to the ash absorption. Furthermore, once the NN is correctly trained, it can process the new data in near real time thanks to its high speed computation (Del Frate et al., 2002). This opportunity makes the inversion method, based on $\mathrm{NN}$ algorithm, very attractive when the computation time speed is a concern.

The first problem handled is the identification of volcanic ash. The second is the retrieval of the ash total mass only where ash has been detected. For both cases two separate NNs have been trained. As it has already been mentioned, observations at the most effective set of channels from MODIS sensor have been considered as input for both NNs, which are channels 28, 31 and 32 (hereafter $\mathrm{CH} 28$, $\mathrm{CH} 31$ and $\mathrm{CH} 32$ ). As target output we have considered the results obtained by the BTD procedure and MODTRAN simulation over a fixed number of MODIS images. Several software packages are available to implement the NNs algorithms, in this work we used the Stuttgard Neural Network Simulator, SNNS (Zell et al., 1995). This is a free general tool that can be very suitable for remote sensing applications, regardless of data type.

\subsection{NNs for volcanic ash detection}

The first problem is the identification of volcanic ash using MODIS data. The input space is composed of three MODIS channels such as $\mathrm{CH} 28, \mathrm{CH} 31$ and $\mathrm{CH} 32$. The last two channels are the same as those considered for the BTD procedure. We observe that the BTD procedure also uses ancillary data that are not taken into account in the $\mathrm{NN}$ algorithm. In the BTD algorithm the atmospheric water vapor correction is computed to improve the detection of the ash. This is achieved using the atmospheric profile derived from ground meteorological stations. Unlike in the BTD algorithm, in the 
$\mathrm{NN}$ architecture the water vapor content is taken into account considering the $\mathrm{CH} 28$ as input to the NN. It is worth noting that $\mathrm{CH} 28$ is centered around $7.3 \mu \mathrm{m}$, where the atmospheric water vapor absorption is particularly strong. Concerning the outputs, we configured the ash detection as a classification problem where the output space is divided in two classes such as Ash and No Ash (hereafter A and NA). The latter is clearly a simplification, as many other possible classes, e.g. meteorological clouds, have not been considered.

To generate the training set (TrS) and the test set (TeS) we chose the acquisition of 28 October 2002 and of 29 October 2002, while the data collected on 23 July 2001, 30 October 2002 and 24 November 2006, have been used for evaluating the classification performance. This approach has been considered in order to assess the generalization capabilities of the NN and the statistical representativeness of the training/test samples. Considering the histograms of the measurements at the three channels and of the estimations of the ash mass computed by the BTD procedure (Fig. 4), it is possible to observe that the 28 October 2002 and 29 October 2002, have a more exhaustive data distribution; this behavior has guided the choice of the two dates for the TrS and TeS.

The input-output samples of the TrS and TeS have been created matching the $\mathrm{CH} 28, \mathrm{CH} 31$ and $\mathrm{CH} 32$ data with the ash map obtained by the BTD procedure, which is the target output (see Fig. 2). Based on the target output map, we have extracted a number $n$ of pixels for $\mathrm{A}$ and an equal number for NA classes at random in order to have a balanced TrS. The $\mathrm{TeS}$ is obtained similarly by the selection of $m$ independent pixels $(m<n)$.

\subsection{NNs for volcanic ash mass retrieval}

The second issue is the retrieval of the total mass of the ash. The input dataset of the $\mathrm{NN}$ is the same as for ash detection, i.e. $\mathrm{CH} 28, \mathrm{CH} 31$ and $\mathrm{CH} 32$, while the output is the ash mass $\left(\mathrm{t} \mathrm{km}^{-2}\right)$. As opposed to the detection, which is a classification exercise, the network performs an estimation of a physical parameter, replicating the BTD model. Therefore the BTD model results (shown in Fig. 3) have been used to extract the target output information to the $\mathrm{NN}$.

The training/test and validation phases are completely focused on the target output regions where the ash plume is identified, according to the BTD ash detection maps (see Fig. 2). Since more than one MODIS image representative of the different events is available, a study on the generalization capability of the NN is possible, as explained below.

For each date $i$ three separate independent subsets have been generated: a training set $\left(\operatorname{TrS} S_{i}\right)$, a test set $\left(\mathrm{TeS}_{i}\right)$ and a validation set $\left(\operatorname{VaS}_{i}\right)$, with $i$, spanning from 1 to $p$, where $p$ is the total amount of acquisitions. Different NNs have been trained with an increasing number of samples. In particular, starting with $i=1$, the $\mathrm{NN}$ at stage $i+1$ is obtained by adding to $\operatorname{TrS} S_{i}$ the elements belonging to $\operatorname{TrS} S_{i+1}$. At each step the performance of the retrieval has been tested on all
Table 2. The Training, Test and Validations sets extracted from the data, for the ash detection exercise.

\begin{tabular}{crrrr}
\hline Data & TrS & TeS & VeS & Tot \\
\hline 28 Oct 2002 & 37416 & 16306 & - & 810000 \\
29 Oct 2002 & 18918 & 8108 & - & 810000 \\
30 Oct 2002 & - & - & 810000 & 810000 \\
24 Nov 2006 & - & - & 810000 & 810000 \\
23 Jul 2001 & - & - & 810000 & 810000 \\
\hline
\end{tabular}

$p$ VaS. It is worth noting that at all $p$-1 stages there is at least one validation test whose samples belong to an image not considered in the training phase. The results expected by this approach are an improvement on the ash mass retrieval performance with an increase in the training samples taken from completely uncorrelated acquisitions. In fact, the inclusion of additional samples should provide a better statistical representation of the phenomenon. This hypothesis will be validated in Sect. 6.2 where the results for the different $V_{i}$ sets, obtained by means of the different $\mathrm{NN}_{i}$, are shown.

\section{Experimental results}

In this section we present the results obtained by applying the proposed procedures for ash cloud detection and the retrieval of ash cloud mass. First the NNs-based ash detection is compared with the results obtained by applying the BTD procedure, and then the performance of the NNs retrieval is shown and discussed.

\subsection{Ash detection results}

As explained in Sect. 5.2, ash detection can be addressed as a classification exercise considering two classes, A and $\mathrm{NA}$, with $\mathrm{TrS}$ and TeS randomly extracted from the 28 October 2002 and 29 October 2002 acquisition dates, while the remaining dates have been used for the validation phase. In Table 2 the patterns forming $\mathrm{TrS}, \mathrm{TeS}$ and VaS, extracted for each acquisition date are shown.

The NN has been trained with a $\mathrm{TrS}$ and a TeS, composed by 56334 and 24414 patterns respectively, extracted from 28-29 October 2002 acquisitions. Each independent $\mathrm{VaS}$, extracted from the remaining data, is composed of 810000 patterns. After a phase where different network topologies, i.e. architectures with different number of hidden units, have been tested, we have selected the least complex topology which gives the best performance. The identified NN is a MLP with a single hidden layer, a sigmoidal activation function for the units, and the following topology: [3]-[10]-[2].

Figure 5a shows the results of the NN classification procedure applied to all MODIS measurements. The ash clouds are well recognized and characterized, indeed the comparison with ash detection carried out by means of the BTD 

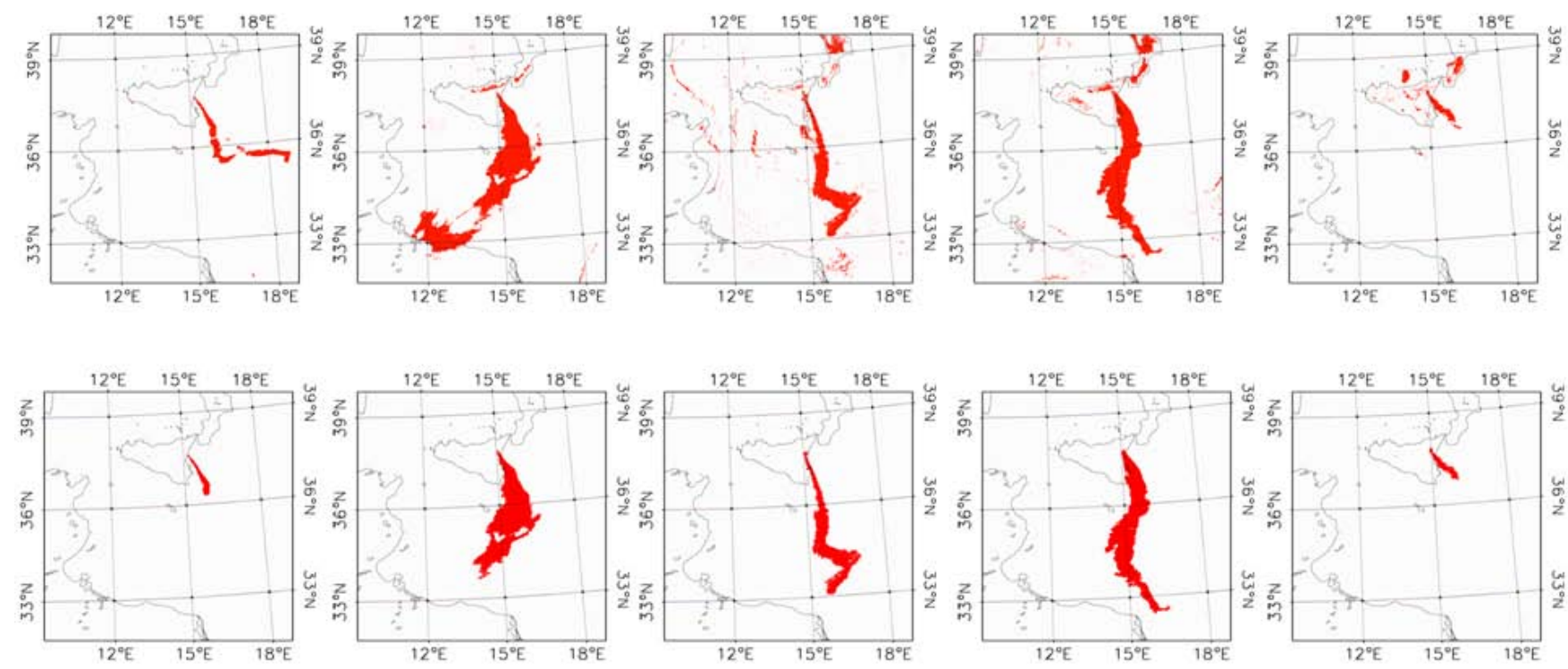

Fig. 5. MODIS NNs procedure ash maps. From left to right: 23 July 2001, 28 October 2002, 29 October 2002, 30 October 2002, and 24 November 2006. (a) Upper part maps without segmentation step. (b) Lower part maps with segmentation step.

technique (see Fig. 2) indicates a very good agreement. Figure $5 \mathrm{a}$ also shows some false positive ash detection since, in the channels considered, the high meteorological clouds exhibit a similar spectral behavior to an ash cloud (see Sect. 4). To avoid these errors, an object-oriented approach has been tested. In particular we considered the pixel corresponding to the volcano's vent as the seed for a region growing algorithm. In this way the resulting ash map is composed of the closest object to the volcano vent while all originally detected areas far from the volcano vent, hence very likely leading to false alarms, are removed (Pulvirenti et al., 2011).

Figure 5b shows the results of the object-oriented procedure. Among the elimination of the false positives, the figure also displays the disappearance of some parts of the ash cloud in its distal part (see for example the 23 July $2001 \mathrm{im}$ age). Such expected effect restrict the use of the segmentation procedure to cases where the volcanic emission is continuous, when we are interested in analyzing the ash cloud impact on the area surrounding the volcano or when we want to focus our study on the volcanic emission processes. The classification accuracy has also been quantitatively analyzed by confusion matrices, showing the level of agreement between two classifications, e.g. BTD and NN, computed with and without the region growing step (see Table 3). Both, the overall accuracy and the $\mathrm{K}$ coefficient, i.e. a measure of interrater agreement (Cohen, 1960), parameters confirm that the results obtained by the developed NN procedure are in agreement with the results obtained by the BTD procedure. Moreover, the post classification segmentation procedure slightly increases the classification accuracies (see right column of Table 3).

\subsection{Ash mass retrieval results}

The approach used for the ash mass retrieval from the $\mathrm{CH} 28$, $\mathrm{CH} 31$, and CH32 has already been explained in Sect. 5.3. In Table 4 the number of patterns extracted from the different acquisition dates for the $\mathrm{TrS}, \mathrm{TeS}$ and $\mathrm{VaS}$ are reported. The adopted network topology is similar to the ash detection, except for the output layer which consists of a single neuron, i.e. [3]-[10]-[1].

To investigate further the relation between the statistical representativeness of the data used in the training phase and the NN retrieval accuracy, an ensemble of scatter plots for the five validation sets has been computed and is shown in Fig. 6. The results, for the VaS extracted from all five dates, reached with the NN trained exclusively with the patterns from 28 October 2002 are shown on top of the figure. The successive scatter plots, arranged in rows, show the results obtained adding training set data from a successive acquisition. For instance, in the second row the scatter plots for all five VaS are also shown, while the training and test sets have been obtained by joining the $\mathrm{TrS}$ and $\mathrm{TeS}$ of the data taken on 28 October 2002 and 29 October 2002 and so on for the others rows. The results are less easily interpretable than those obtained for ash detection, therefore a brief comment seems appropriate in evaluating the effectiveness of the proposed method. The first evidence is that the retrieval results are already positive with the $\mathrm{NN}$ trained only with the $\mathrm{TrS}$ and $\mathrm{TeS}$ extracted from the first acquired date (28 October 2002). This is probably due to the large number of patterns considered in the first training set. For the majority of the input-output patterns of the other four VaS the statistical representativeness of the $\operatorname{TrS}$ seem to be appropriate 
Table 3. Confusion Matrix assess the classification accuracy on the validation sets: Left column results of NN. Right column results of NN and segmentation post processing.

\begin{tabular}{|c|c|c|c|c|c|c|c|}
\hline \multicolumn{4}{|c|}{23 July 2001} & \multicolumn{4}{|c|}{23 July 2001} \\
\hline \multirow[b]{2}{*}{ NNs } & \multirow[b]{2}{*}{$\begin{array}{c}\text { Ash } \\
\text { Not Ash }\end{array}$} & \multicolumn{2}{|c|}{ BTD } & \multirow[b]{2}{*}{ NNs } & \multicolumn{3}{|c|}{ BTD } \\
\hline & & $\begin{array}{l}\text { Ash } \\
8159 \\
1164\end{array}$ & $\begin{array}{c}\text { Not Ash } \\
1163 \\
799514\end{array}$ & & $\begin{array}{c}\text { Ash } \\
\text { Not Ash }\end{array}$ & $\begin{array}{l}\text { Ash } \\
2289 \\
7034\end{array}$ & $\begin{array}{c}\text { Not Ash } \\
201 \\
800476\end{array}$ \\
\hline \multicolumn{4}{|c|}{$\begin{array}{c}\text { Overall Accuracy }=99.7 \% \\
K \text { Coefficient }=0.87\end{array}$} & \multicolumn{4}{|c|}{$\begin{array}{c}\text { Overall Accuracy }=99.0 \% \\
K \text { Coefficient }=0.83\end{array}$} \\
\hline \multicolumn{4}{|c|}{30 October 2002} & \multicolumn{4}{|c|}{30 October 2002} \\
\hline \multirow[b]{2}{*}{ NNs } & \multirow[b]{2}{*}{$\begin{array}{c}\text { Ash } \\
\text { Not Ash }\end{array}$} & \multicolumn{2}{|c|}{ BTD } & \multirow[b]{2}{*}{ NNs } & \multirow[b]{2}{*}{$\begin{array}{c}\text { Ash } \\
\text { Not Ash }\end{array}$} & \multicolumn{2}{|c|}{ BTD } \\
\hline & & $\begin{array}{c}\text { Ash } \\
23922 \\
565\end{array}$ & $\begin{array}{c}\text { Not Ash } \\
21630 \\
763815\end{array}$ & & & $\begin{array}{c}\text { Ash } \\
23755 \\
1164 \\
\end{array}$ & $\begin{array}{c}\text { Not Ash } \\
11714 \\
773731\end{array}$ \\
\hline \multicolumn{4}{|c|}{$\begin{array}{c}\text { Overall Accuracy }=97.2 \% \\
K \text { Coefficient }=0.67\end{array}$} & \multicolumn{4}{|c|}{$\begin{array}{c}\text { Overall Accuracy }=98.4 \% \\
K \text { Coefficient }=0.78\end{array}$} \\
\hline \multicolumn{4}{|c|}{24 November 2006} & \multicolumn{4}{|c|}{24 November 2006} \\
\hline & & \multicolumn{2}{|c|}{ BTD } & & & \multicolumn{2}{|c|}{ BTD } \\
\hline $\mathrm{NN}$ & $\begin{array}{c}\text { Ash } \\
\text { Not Ash }\end{array}$ & $\begin{array}{c}\text { Ash } \\
2673 \\
937\end{array}$ & $\begin{array}{c}\text { Not Ash } \\
4833 \\
801468\end{array}$ & $\mathrm{NN}$ & $\begin{array}{c}\text { Ash } \\
\text { Not Ash }\end{array}$ & $\begin{array}{l}\text { Ash } \\
2484 \\
1126\end{array}$ & $\begin{array}{c}\text { Not Ash } \\
397 \\
805904\end{array}$ \\
\hline \multicolumn{4}{|c|}{$\begin{array}{c}\text { Overall Accuracy }=99.2 \% \\
K \text { Coefficient }=0.47\end{array}$} & \multicolumn{4}{|c|}{$\begin{array}{c}\text { Overall Accuracy }=99.8 \% \\
K \text { Coefficient }=0.76\end{array}$} \\
\hline
\end{tabular}

Table 4. The Training, Test and Validations sets for the ash mass retrieval exercise.

\begin{tabular}{lrrrrr}
\hline Data & TrS & TeS & VaS & Tot Ash & Tot \\
\hline 28 Oct 2002 & 11841 & 3634 & 2742 & 18271 & 810000 \\
29 Oct 2002 & 5780 & 1774 & 1338 & 8892 & 810000 \\
30 Oct 2002 & 8700 & 2670 & 2014 & 13384 & 810000 \\
24 Nov 2006 & 1633 & 501 & 378 & 2512 & 160000 \\
23 Jul 2001 & 6060 & 1865 & 1398 & 9323 & 810000 \\
\hline
\end{tabular}

(see Fig. 4). In fact the Pearson correlation coefficients between the true and the retrieved parameters are always larger or equal to 0.95 (see the first row of Fig. 6), while the slope of the regression line is closer to one with the increase of the training/test patterns from different dates. The latter is indeed an important indicator for evaluating ash mass retrieval capability of the NN (see Fig. 6), because when the number of training patterns increases an improvement of the parameter can be observed.

The above analysis seems to uphold the effectiveness of the proposed approach: when increasing the training data, an increase of the retrieval accuracy can be appreciated. This tendency can be evaluated from the ensemble of scatter plots shown in Fig. 6, as well as considering the trend of the rmse values for the five VaS sets obtained by means of the five different NNs (see Table 5).

Considering the evidence discussed above for computing ash total mass maps we have adopted the NN5, trained with the total training set. The retrieved ash mass maps are shown in Fig. 7. The retrieval has only been done where the ash has been detected by the NN detection algorithm with region growing algorithm previously described. The visual analysis of the maps confirms the positive results obtained with the proposed approach. In particular the comparison of BTD (see Fig. 3) and NN (see Fig. 7) results shows very similar concentration (i.e. colours) and shape features, thus evidencing the ability of the NN algorithm to approximate the results provided by the BTD MODTRAN-based method.

\section{Conclusions}

In this work a NN procedure for detecting volcanic ash clouds and retrieving the ash clouds' mass has been implemented and discussed. As test cases several events that occurred during the 2001, 2002 and 2006 eruptions on Mt. Etna 

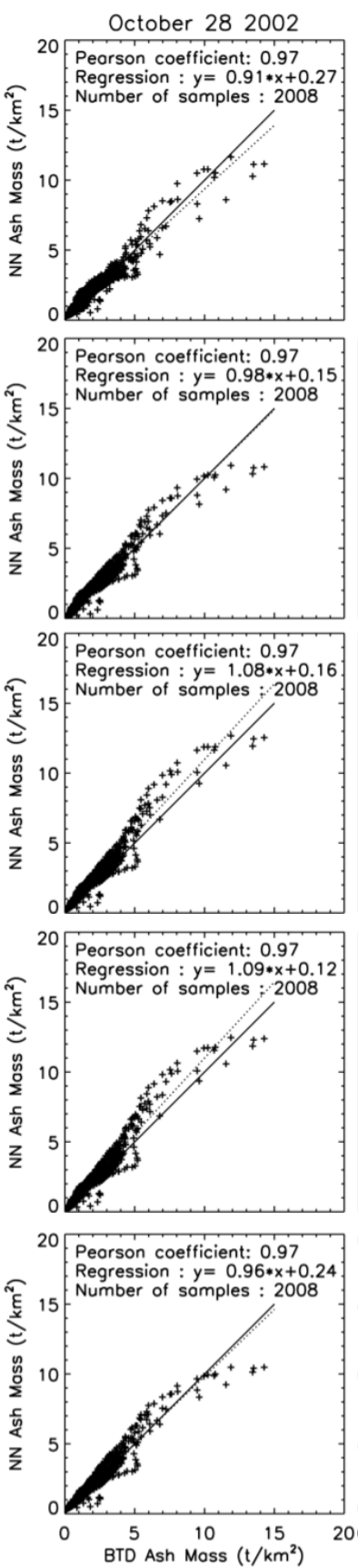

October 292002

Peorson coefficient: 0.98 Regression : $y=0.74 * x+0.17$ Number of somples : 1338
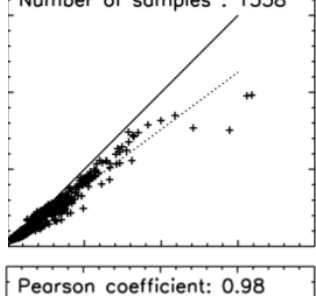
Regression : $y=0.87 * x+0.13$ Number of somples : 1338
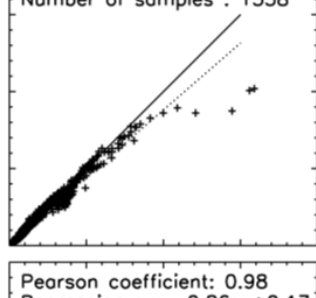
Regression : $y=0.86 * x+0.17$ Regression : $y=0.86 * x+0.17$
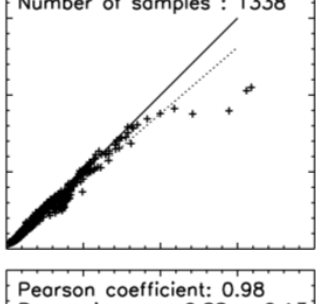
Regression : $y=0.88 * x+0.1$ Number of somples : 1338
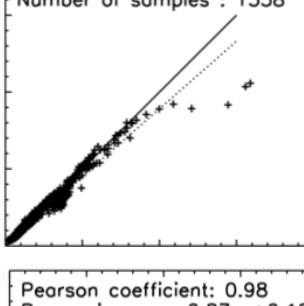
Reorson coefficient: 0.98 Regression : $y=0.87 * x+0.18$

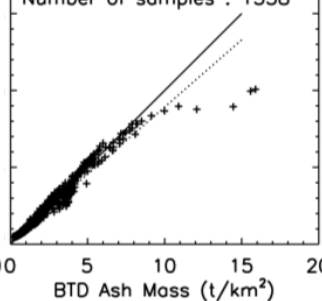

October 302002

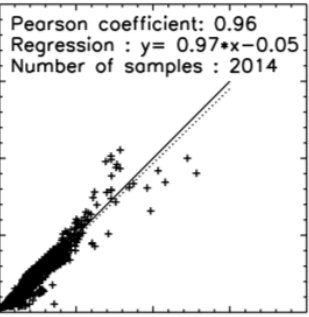

Peorson coefficient: 0.97 Regression : $y=0.97 * x-0.03$ Number of somples : 2014
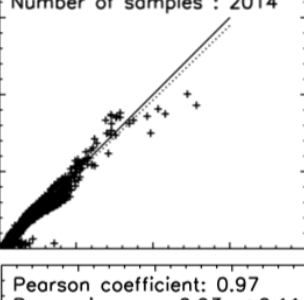
Regression : $y=0.93 * x+0.11$ Regression : $y=0.93 * x+0.1$

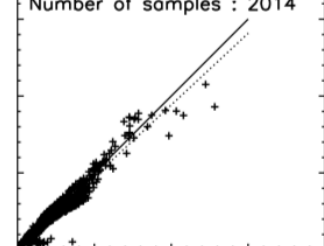

Peorson coefficient: 0.97 Regression : $y=0.93 * x+0.06$ Number of somples : 2014
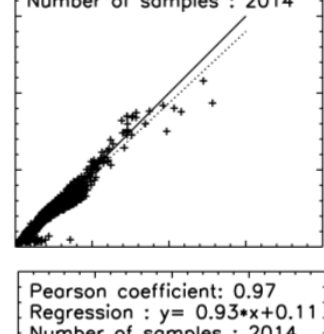

Number of somples : 2014

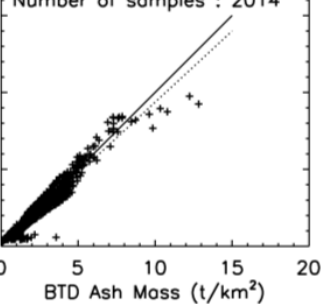

November 242006

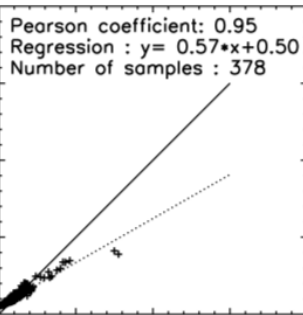

Peorson coefficient: 0.97 Regression : $y=0.83 * x+0.60$
Number of somples : 378
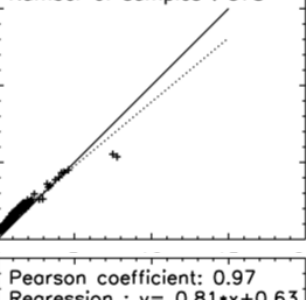
Regression : $y=0.81 * x+0.63$

Number of somples : 378

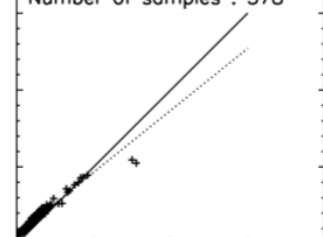

Peorson coefficient: 0.97 Regression : $y=0.82 * x+0.60$ Number of somples : 378
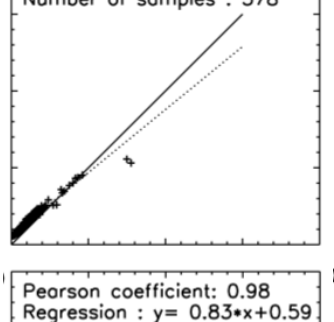
Regression : $y=0.83 * x+0.59$ Number of somples: 378

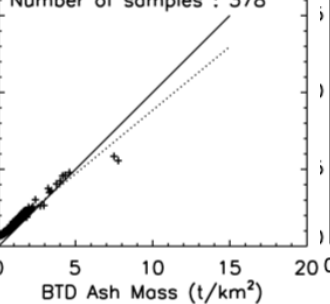

July 232001

Peorson coefficient: 0.95 Regression : $y=0.53 * x+0.28$ Number of somples : 1398
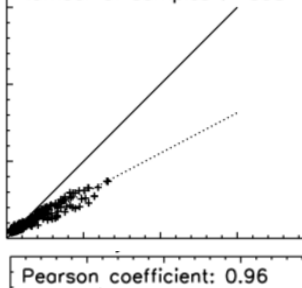
Regression : $y=0.77 * x+0.00$ Number of somples : 1398

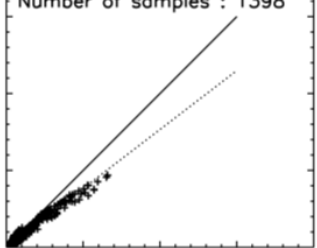

Peorson coefficient: 0.97 Regression : $y=0.77 * x+0.11$ - Number of somples : 1398
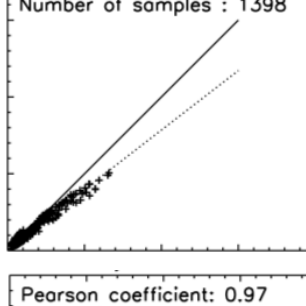
Regression : $y=0.74 * x+0.10$ Number of somples : 1398

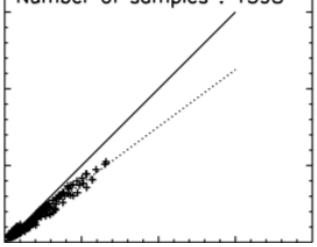

Peorson coefficient: 0.97 Regression : $y=0.78 * x+0.07$ Number of somples : 1398

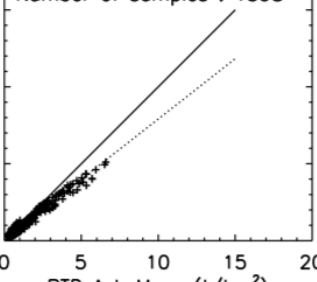

Fig. 6. Scatter plots for the five $V$ sets, from left to right: 28 October 2002, 29 October 2002, 30 October 2002,24 November 2006 , 23 July 2001. From top to bottom results from: NN1 (28 October 2002). NN2 (28 October $2002+29$ October 2002). NN3 (28 October 2002 +29 October $2002+30$ October 2002). NN4 (28 October $2002+29$ October $2002+30$ October $2002+24$ November 2006). NN5 $(28$ October $2002+29$ October $2002+30$ October $2002+24$ November $2006+23$ July 2001).

and imaged by MODIS instrument have been considered. It has been shown that the neural approach drastically reduces the computational time required for data processing. Indeed, the ash cloud detection and the production of the ash clouds' mass maps are produced in a few minutes. The technique developed is therefore extremely attractive during a crisis phase, when a fast processing of the results is a mandatory requirement. On the other hand, the improvement in processing time is achieved without lowering the accuracy characterizing the estimated quantities. Once the learning phase is over, when tested on data not belonging to the training set, the NN provides results in accordance with those given by the BTD-based technique. This is true for both the ash detection and the mass retrieval cases. In particular the detected ash 
Table 5. The rmse values for the extracted Validations sets.

\begin{tabular}{|c|c|c|c|c|c|}
\hline 28 Oct 2002 & $\begin{array}{l}\text { RMSE VaS } \\
29 \text { Oct } 2002\end{array}$ & $\begin{array}{r}\text { RMSE VaS } \\
30 \text { Oct } 2002\end{array}$ & $\begin{array}{r}\text { RMSE VaS } \\
24 \text { Nov } 2006\end{array}$ & $\begin{array}{l}\text { RMSE VaS } \\
23 \text { Jul } 2001\end{array}$ & RMSE VaS \\
\hline NN1: 28 Oct 2002 & 0.3756 & 0.5217 & 0.4247 & 0.4831 & 0.4032 \\
\hline NN2: 28 Oct $2002+29$ Oct 2002 & 0.3573 & 0.3580 & 0.3408 & 0.4722 & 0.3101 \\
\hline NN3: 28 Oct $2002+29$ Oct $2002+30$ Oct 2002 & 0.4619 & 0.3405 & 0.3181 & 0.4712 & 0.2417 \\
\hline NN4: 28 Oct $2002+29$ Oct $2002+30$ Oct $2002+24$ Nov 2006 & 0.4544 & 0.3348 & 0.3263 & 0.4528 & 0.2510 \\
\hline $\begin{array}{l}\text { NN5: } 28 \text { Oct } 2002+29 \text { Oct } 2002+30 \text { Oct } 2002+24 \text { Nov } 2006 \\
+23 \text { Jul } 2001\end{array}$ & 0.4544 & 0.3348 & 0.3263 & 0.4528 & 0.2600 \\
\hline
\end{tabular}
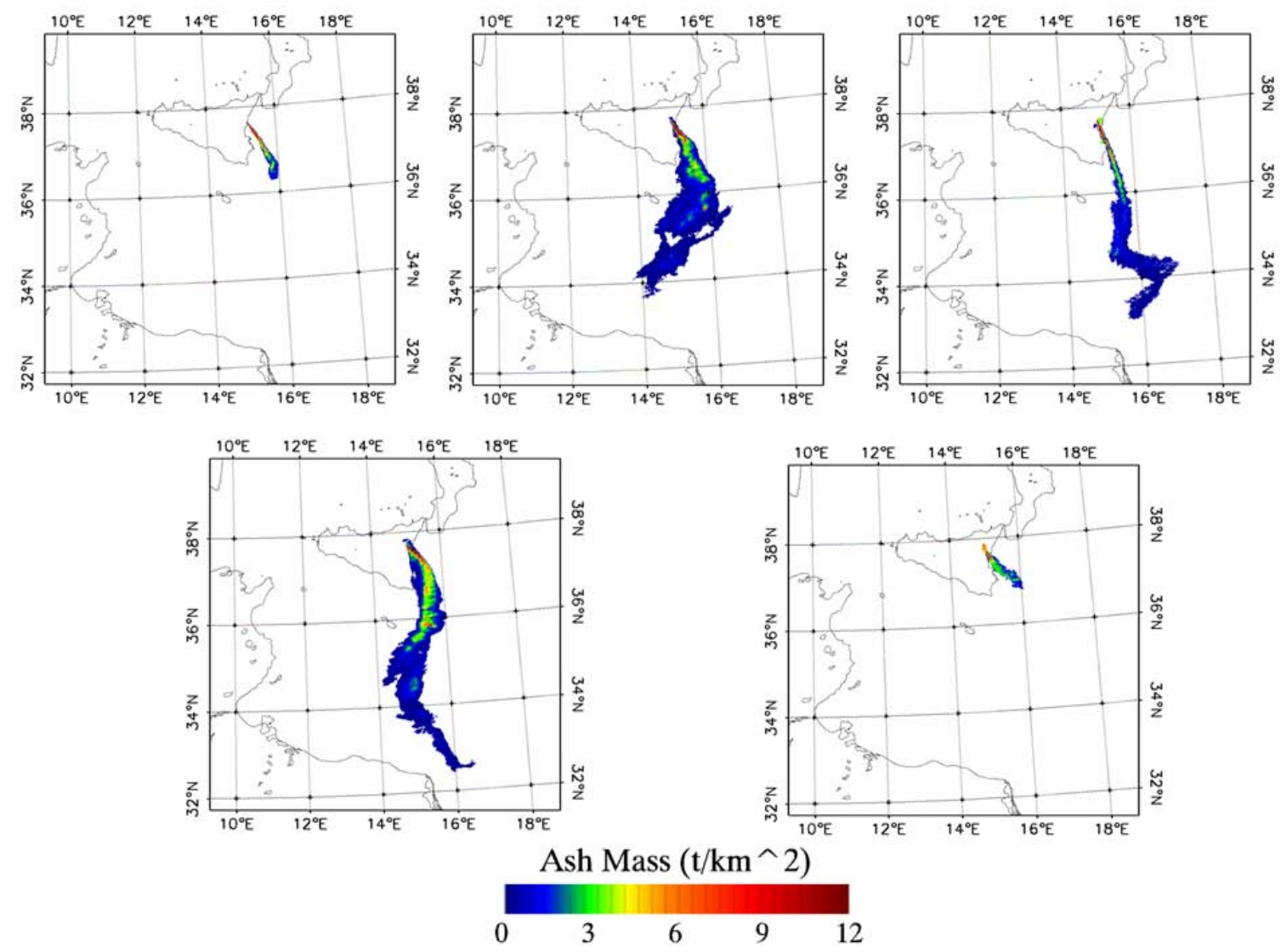

Fig. 7. NNs MODIS Ash mass maps from five different dates. Top Plates, from left to right: 23 July 2001,28 October 2001 and 29 October 2002. Bottom Plates, from left to right: 30 October 2002 and 24 November 2006.

maps have a mean $\mathrm{K}$-coefficient around 0.8, while the regression curves of ash mass retrievals have a rmse close to 0.3. An object-oriented approach has also been applied to avoid the false positive ash pixels detected by the technique and induced by the presence of high meteorological clouds. The comparison with the ground truth shows that, even if it yields a benefit in terms of classification accuracy, the segmentation procedure also eliminates actual ash clouds appearing in the distal part. This latter effect limits the use of the procedure only in the particular cases where the volcanic emission is continuous, thus when we are interested in analyzing the ash cloud impact on the area surrounding the volcano or when we want to focus our study on the volcanic emission processes.
It must be stressed that the proposed inversion scheme can easily be extended in order to consider additional bands, hence to make more information available as input. In fact, future improvements include the use of visible and near infrared channels for meteorological clouds detection, and the retrieval of ash cloud optical depth and effective radius. The generalization capabilities of the NN in this field is another aspect that can be investigated further by considering different satellite sensors (as the Spin Enhanced Visible and Infrared Imager (SEVIRI)), different volcanic eruptions in time, as well for different test sites. 
Acknowledgements. S. Corradini research contract has been partially funded by the European Space Agency's Earth Observation Envelope Programme (EOEP) - Data User Element (project SAVAA).

Edited by: O. Torres

\section{References}

Aiuppa, A., Giudice, G., Gurrieri, S., Liuzzo, M., Burton, M., Caltabiano, T., McGonigle, A. J. S., Salerno, G., Shinohara, H., and Valenza M.: Total volatile flux from Mount Etna, Geophys. Res. Lett., 35, L24302, doi:10.1029/2008GL035871, 2008.

Allard, P., Carbonnelle, J., Dajlevic, D., Le Bronec, J., Morel, P., Robe, M. C., Maurenas, J. M., Pierret, R. F., Martins, D., Sabroux, J. C., and Zettwoog, P.: Eruptive and diffuse emission of $\mathrm{CO}_{2}$ from Mount Etna, Nature, 351, 387-391, 1991.

Anderson, G. P., Wang, J., and Chrtwynd, J. H.: MODTRAN3: An update and recent validation against airborne high resolution inferometer measurements, In Summaries of the Fifth Annual Jet Propulsion Laboratory Airborne Earth Science Workshop, 95-1 (1), 5-8, 1995.

Atkinson, P. M. and Tatnall, A. R. L.: Neural networks in remote sensing, Int. J. Remote Sens., 18, 699-709, 1997.

Bankert, R. L.: Cloud classification of AVHRR imagery in maritime regions using a probabilistic neural network, J. Appl. Meteorol., 33, 909-918, 1994.

Barnes, W. L., Pagano, T. S., and Salomonson, V. V.: Prelaunch characteristics of the Moderate Resolution Imaging Spectroradiometer (MODIS) on EOS-AMI, IEEE Trans. Geosci. Remote Sens., 36, 1088-1100, 1998.

Barton, I. J. and Takashima, T.: An AVHRR investigation of surface emissivity near Lake Eyre, Australia, Remote Sens. Environ., 20, 153-163, 1986.

Benediktsson, J. A. and Sveinsson, J. R.: Feature extraction for multisource data classification with artificial neural networks, Int. J. Remote Sens., 18, 727-740, 1997.

Benediktsson, J. A., Swain, P. H., and Ersoy, O. K.: Neural network approaches versus statistical methods in classification of multisource remote sensing data, IEEE Trans. Geosci. Remote Sens., 28, 540-552, 1990.

Benediktsson, J. A., Swain, P. H., and Esroy, O. K.: Conjugategradient neural networks in classification of multisource and very-high-dimensional remote sensing data, Int. J. Remote Sens., 14, 2883-2903, 1993.

Berk, A., Bernstein, L. S., Anderson, G. P., Acharya, P. K., Robertson, D. C., Chetwynd, J. H., and Adler-Golden, S. M.: Modtran cloud and multiple scattering upgrades with application to AVIRIS, Remote Sens. Environ., 65, 367-375, 1998.

Bishop, C. M.: Neural Networks for Pattern Recognition, Oxford University Press, 1995.

Blackwell, W. J.: A neural-network technique for the retrieval of atmospheric temperature and moisture profiles from high spectral resolution sounding data, IEEE Trans. Geosci. Remote Sens., 43, 2535-2546, 2005.

Butler, C. T., Meredith, R. V. Z., and Stogryn, A. P.: Retrieving atmospheric temperature parameters from DMSP SSM/T-1 data with a neural network, J. Geophys. Res., 101, 7075-7083, 1996.
Cabrera-Mercader, C. R. and Staelin, D. H.: Passive microwave relative humidity retrievals using feed forward neural networks, IEEE Trans. Geosci. Remote Sens., 33, 1324-1328, 1995.

Carpenter, G. A., Gjaja, M. N., Gopal, S., and Woodcock, C. E.: ART neural networks for remote sensing: vegetation classification from Landsat TM and terrain data, IEEE Trans. Geosci. Remote Sens., 35, 308-325, 1997.

Chini, M., Pacifici, F., Emery, W. J., Pierdicca, N., and Del Frate, F: Comparing Statistical and Neural Network Methods Applied to Very High Resolution Satellite Images Showing Changes in Man-Made Structures at Rocky Flats, IEEE Trans. Geosci. Remote Sens., 46, 1812-1821, 2008.

Chini, M., Pacifici, F., and Emery, W. J.: Morphological operators applied to X - band SAR for urban land use classification, Proc. IEEE/IGARSS 2009, IV 506-IV 509, 2009.

Churnside, J. H., Stermitz, T. A., and Schroeder, J. A.: Temperature profiling with neural network inversion of microwave radiometer data, J. Atmos. Oceanic Technol., 11, 105-109, 1994.

Civco, D. L.: Artificial neural networks for land-cover classification and mapping, Int. J. Geogr. Inf. Sys., 7, 173-186, 1993.

Cohen, J.: A coefficient of agreement for nominal scales, Educ. Psychol. Meas., 20, 37-46, 1960.

Corradini, S., Spinetti, C., Carboni, E., Tirelli, C., Buongiorno, M. F., Pugnaghi, S., and Gangale, G.: Mt. Etna tropospheric ash retrieval and sensitivity analysis using Moderate Resolution Imaging Spectroradiometer measurements, J. Atmos. Remote. Sens., 2, 023550, doi:10.1117/1.3046674, 2008a.

Corradini, S., Merucci, L., Prata, F., Silvestri, M., Musacchio, M., Spinetti, C., Piscini, A., and Buongiorno, M. F.: $\mathrm{SO}_{2}$ and ash plume retrievals using MSG-SEVIRI measurements, Test case: 24 November 2006 Mt. Etna eruption, IEEE USEREST Workshop, Naples 11-14 November, 2008b.

Corradini, S., Merucci, L., Prata, A. J., and Piscini, A.: Volcanic ash and $\mathrm{SO}_{2}$ in the 2008 Kasatochi eruption: Retrievals comparison from different IR satellite sensors, J. Geophys. Res., 115, D00L21, doi:10.1029/2009JD013634, 2010.

Corradini, S., Merucci, L., and Arnau, F.: Volcanic ash cloud properties: comparison between MODIS satellite retrievals and FALL3D transport model, IEEE Geosci. Remote Sens. Lett., 8, 248-252, 2011.

Cybenko, G.: Approximation by superpositions of a sigmoidal function, Math. Control. Signal. Syst., 2, 303-314, 1989.

Del Frate, F. and Schiavon, G.: Nonlinear principal component analysis for the radiometric inversion of atmospheric profiles by using neural networks, IEEE Trans. Geosci. Remote Sens., 37, 2335-2342, 1999.

Del Frate, F., Ortenzi, A., Casadio, S., and Zehner, C.: Application of neural algorithms for a real-time estimation of ozone profiles from GOME measurements", IEEE Trans. Geosci. Remote Sens., 40), 2263-2270, 2002.

EUMETSAT Report: Monitoring volcanic ash from space ESAEUMETSAT workshop on the 14 April to 23 May 2010 eruption at the Eyjafjöll volcano, South Iceland, edited by: Zehner, C., ESA/ESRIN, May 26-27, available at: http://earth.eo.esa.int/ workshops/Volcano/files/STM-280_ash101004_V2.pdf, 2010.

Foody, G. M.: Using prior knowledge in artificial neural network classification with a minimal training set, Int. J. Remote Sens., 16, 301-312, 1995a.

Foody, G. M.: Land cover classification using an artificial neural 
network with ancillary information, Int. J. Geogr. Inf. Sys., 9, 527-542, 1995b.

Funahashi, K.: On the approximate realization of continuous mappings by neural net-works, Neural Networks, 2, 183-192, 1989.

Gardner, M. W. and Dorling, S. R.: Artificial neural networks (the multilayer perceptron) - A review of applications in the atmospheric sciences, Atmos. Environ., 32, 2627-2636, 1998.

Haykin, S.: Neural Networks: A Comprehensive Foundation, Macmillan, New York, 1994.

Hillger, D. W. and Clark, J. D.: Principal component image analysis of MODIS for volcanic ash. Part I: Most Important Bands and Implications for Future GOES Imagers, J. Appl. Meteorol., 41, 985-1001, 2002.

Hornik, K. M., Stinchcombe, M., and White, H: Multilayer feedforward networks are universal approximators, Neural Networks, 2, 359-366, 1989.

Hsieh, W. W. and Tang, B.: Applying neural network models to prediction and data analysis in meteorology and oceanography, Bull. Am. Meteorol. Soc., 79, 1855-1870, 1998.

Lee, J., Weger, R. C., Sengupta, S. K., and Welch, R.M.: A neural network approach to cloud classification, IEEE Trans. Geosci. Remote Sens., 28, 846-855, 1990.

Lippmann, R.: An introduction to computing with neural nets, IEEE ASSP Magazine, 4, 4-22, 1987.

Mas, J. F. and Flores, J. J.: The application of artificial neural networks to the analysis of remotely sensed data, Int. J. Remote Sens., 29, 617-663, 2008.

Miller, T. P. and Casadevall, T. J.: Volcanic Ash Hazards to Aviation, Encyclopedia of Volcanoes, edited by: Sigurdsson, H., Academic Press, San Diego, California, 915-930, 2000.

Müller, M. D., Kaifel, A. K., Weber, M., Tellmann, S., Burrows, J. P., and Loyola, D.: Ozone profile retrieval from Global Ozone Monitoring Experiment (GOME) data using a neural network approach (Neural Network Ozone Retrieval System (NNORSY)), J. Geophys. Res., 108, 4497, doi:10.1029/2002JD002784, 2003.

Neal, C. A., Mc Gimsey, R. G., Gardner, C. A., Harbin, M. L., and Nye, C. J.: Tephra-fall from 1992 eruptions of Crater Peak, Mount Spurr Volcano, AK: A preliminary report on distribution, stratigraphy and composition, US Geol. Surv. Bull., 2139, 65-79, 1995.

Oxford University, Atmospheric Oceanic and Planetary Physics Dept., EODG group Mie Code: Light scattering routines, available at: http://www.atm.ox.ac.uk/code/mie/index.html (last access: 1 December 2011), 2006.

Pacifici, F., Chini, M., and Emery, W. J.: A neural network approach using multi-scale textural metrics from very high resolution panchromatic imagery for urban land-use classification, Remote Sens. Environ., 113, 1276-1292, 2009.

Platt, C. M. R. and Prata, A. J.: Nocturnal effects in the retrieval of land surface temperatures from satellite measurements, Remote Sens. Environ., 45, 127-136, 1993.

Potts, R. J. and Ebert, E. E.: On the detection of volcanic ash in NOAA AVHRR infrared satellite imagery, in: 8th Australian remote sensing conference, Canberra (25-29), Floreat, Western Australia, Remote Sensing and Photogrammetry Association Australia (March), 1996.

Prata, A. J.: Infrared radiative transfer calculations for volcanic ash clouds, Geophys. Res. Lett., 16, 1293-1296, 1989a.
Prata, A. J.: Observation of volcanic ash clouds using AVHRR-2 radiances, Int. J. Remote Sens., 10, 751-761, 1989 b.

Prata, A. J. and Grant, I. F.: Determination of mass loadings and plume heights of volcanic ash clouds from satellite data, CSIROAtmosph, Res. Tech. Pap., 48, Australia, 2001.

Prata, A. J. and Kerkmann, J.: Simultaneous retrieval of volcanic ash and $\mathrm{SO}_{2}$ using MSG-SEVIRI measurements, Geophys. Res. Lett., 34, L05813, doi:10.1029/2006GL028691, 2007.

Prata, F., Bluth, G., Rose, W., Schneider, D., and Tupper, A.: Comments on "Failures in detecting volcanic ash from a satellitebased technique", Remote Sens. Environ., 78, 341-346, 2001.

Pulvirenti, L., Chini, M., Pierdicca, N., Guerriero, L., and Ferrazzoli, P.: Flood monitoring using multi-temporal COSMOSkyMed data: image segmentation and signature interpretation, Remote Sens. Environ., 115, 990-1002, 2011.

Sellitto, P., Bojkov, B. R., Liu, X., Chance, K., and Del Frate, F.: Tropospheric ozone column retrieval at northern mid-latitudes from the Ozone Monitoring Instrument by means of a neural network algorithm, Atmos. Meas. Tech., 4, 2375-2388, doi:10.5194/amt-4-2375-2011, 2011a.

Sellitto, P., Del Frate, F., Solimini, D., and Casadio, S.: Tropospheric Ozone Column Retrieval From ESA-Envisat SCIAMACHY Nadir UV/VIS Ra- diance Measurements by Means of a Neural Network Algorithm, IEEE Trans. Geosci. Remote Sens., 49, 1-14, doi:10.1109/TGRS.2011.2163198, 2011 b.

Simpson, J. J., Hufford, G. L., Pieri, D., and Berg, J. S.: Failures in detecting volcanic ash from a satellite-based technique, Remote Sens. Environ., 72, 191-217, 2000.

Tupper, A., Carn, S., Davey, J., Kamada, Y., Potts, R., and Prata, F.: An evaluation of volcanic cloud detection techniques during recent significant eruption in the western Ring of Fire, Remote Sens. Environ., 91, 27-46, 2004.

Volz, F. E.: Infrared optical constants of ammonium sulfate, Sahara dust, volcanic pumice and fly ash, Appl. Optics, 12, 564-568, 1973.

Watson, I. M., Realmuto, V. J., Rose, W. I., Prata, A. J., Bluth, G. J. S., Gu, Y., Bader, C. E., and Yu, T.: Thermal infrared remote sensing of volcanic emissions using the moderate resolution imaging spectroradiometer, J. Volcanol. Geoth. Res., 135, 75-89, 2004.

Wen, S. and Rose, W.: Retrieval of sizes and total masses of particles in volcanic aerosol clouds using AVHRR bands 4 and 5, J. Geophys. Res., 99, 5421-5431, 1994.

Yamanouchi, T., Suzuki, K., and Kawaguchi, S.: Detection of clouds in Antarctica from infrared multispectral data of AVHRR, J. Meteo. Soc. Jpn., 65, 949-961, 1987.

Yu, T., Rose, W. I., and Prata, A. J.: Atmospheric correction for satellite-based volcanic ash mapping and retrievals using split window IR data from GOES and AVHRR, J. Geophys. Res., 107, D16, doi:10.1029/2001JD000706, 2002.

Zell, A., Mamier, G., Vogt, M., Mach, N., Huebner, R., Herrmann, K. U., Soyez, T., Schmalzl, M., Sommer, T., Hatzigeogiou, A., Doering, S., and Posselt, D.: SNNS Stuttgart Neural Network Simulator User Manual, Report N6/95, University of Stuttgart, Institute for Parallel and Distributed High Performance Systems, Stuttgart, Germany, 1995. 